\title{
FEEDBACK-SEEKING BEHAVIOUR AND LEADER SUPPORT: AN ATTACHMENT THEORY PERSPECTIVE
}

\author{
by \\ Laura Hymas \\ Bachelor of Science, Honours, Psychology and Health Studies, 2017, University of Toronto
}

A thesis presented to Ted Rogers School of Management at Ryerson University

in partial fulfillment of the requirements for the degree of

Master of Science in Management

in the program of

Master of Science in Management

Toronto, Ontario, Canada, 2020

(C) Laura Hymas, 2020 


\section{AUTHOR'S DECLARATION FOR ELECTRONIC SUBMISSION OF A THESIS}

I hereby declare that I am the sole author of this thesis. This is a true copy of the thesis, including any required final revisions, as accepted by my examiners. I authorize Ryerson University to lend this thesis to other institutions or individuals for the purpose of scholarly research. I further authorize Ryerson University to reproduce this thesis by photocopying or by other means, in total or in part, at the request of other institutions or individuals for the purpose of scholarly research. I understand that my thesis may be made electronically available to the public. 


\begin{abstract}
Feedback-Seeking Behaviour and Leader Support: An Attachment Theory Perspective Master of Science in Management, Human Resources and Organizational Behaviour, 2020 Ted Rogers School of Management at Ryerson University Laura Hymas
\end{abstract}

Organizations rely heavily on human capital to succeed and maintain competitive advantage in today's fierce economic environment. Organizations that make effective use of feedback practices have greater business growth and more productive employees. In this thesis, I apply Attachment Theory to organizational research to more thoroughly understand working relationships and proactive behaviour. My study explores the relationship between attachment style and frequency of feedback-seeking behaviour, and the impact of leader support. Examining these relationships is important because feedback sharing is a critical tool in the workplace to encourage improved workplace behaviour and performance, however, there is a critical gap in the literature regarding the factors that encourage or discourage this behaviour. The results demonstrate a positive relationship between attachment anxiety and frequency of feedbackseeking, and a negative relationship between attachment avoidance and frequency of feedbackseeking, although neither finding is significant. Further, the interaction effect of leader support was also not significant. Future research should consider replicating the study and making appropriate modifications to mitigate limitations such as sample size and selection bias. 


\section{Acknowledgements}

I would like to express my very great appreciation to Dr. Fei Song, my research supervisor, for her patience, guidance, encouragement and useful critiques of this research. Her advice and assistance during the planning and development of this paper was invaluable to me and I have deep gratitude for her willingness to give her time so generously. This thesis would not have been possible without her consistent and reliable support.

I would also like to extend my sincerest gratitude to Dr. Annika Hillebrandt and Dr. Kristyn Scott, my thesis committee members, for their professional guidance, support and suggestions, which have contributed greatly to the improvement of this research work.

Finally, to my course instructors and classmates, thank you for your immense knowledge and support. Your encouragement has made this journey both enjoyable and meaningful. 


\section{Table of Contents}

AUTHOR'S DECLARATION FOR ELECTRONIC SUBMISSION OF A THESIS...................... ii

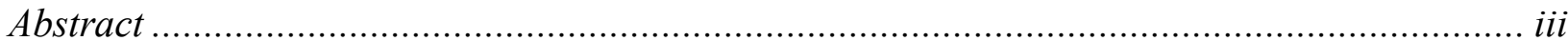

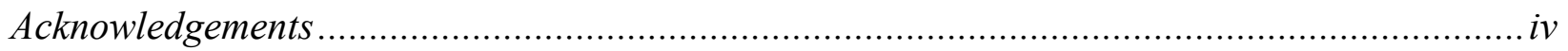

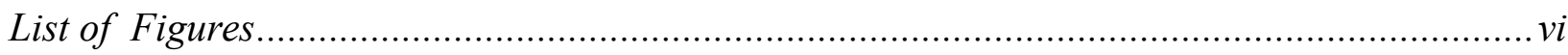

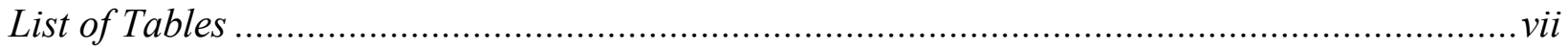

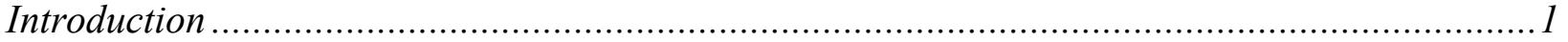

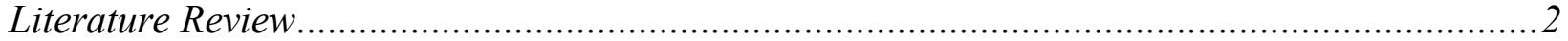

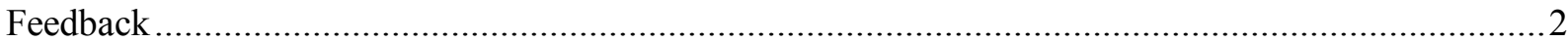

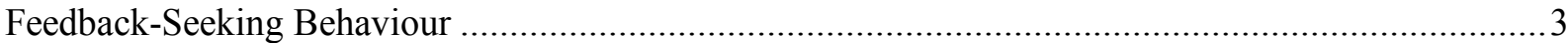

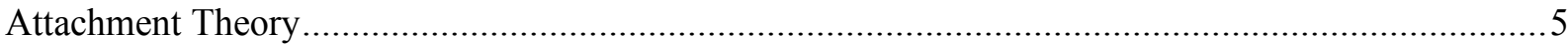

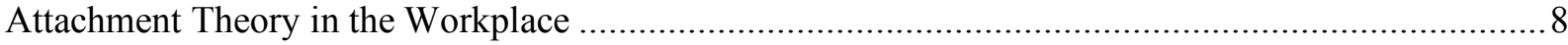

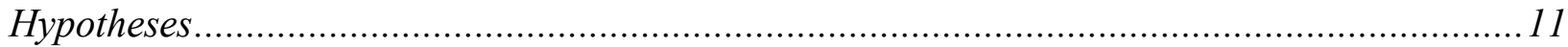

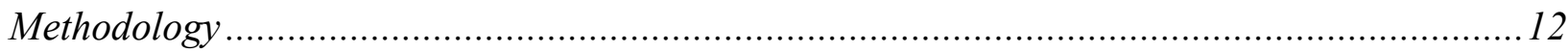

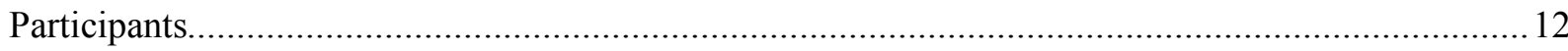

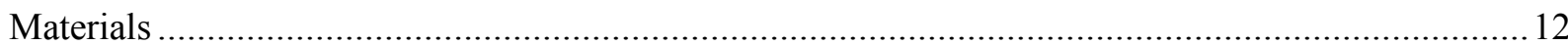

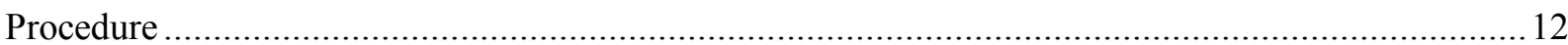

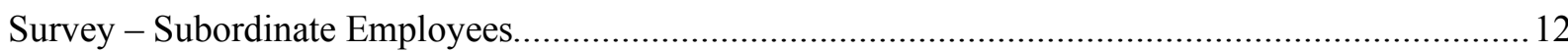

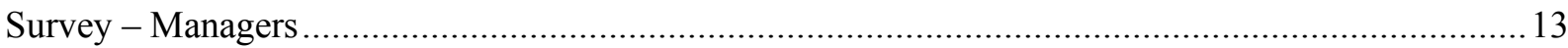

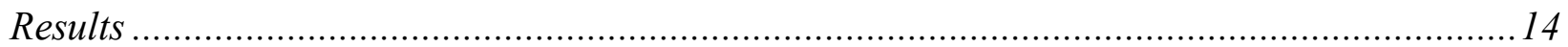

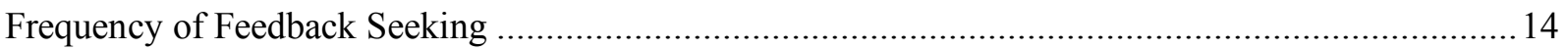

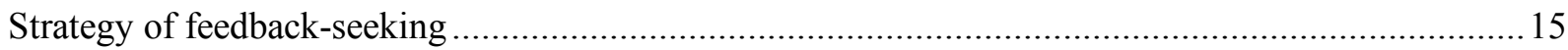

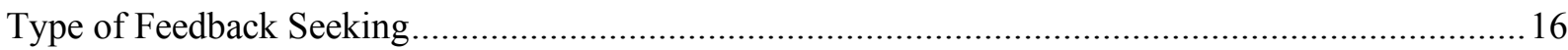

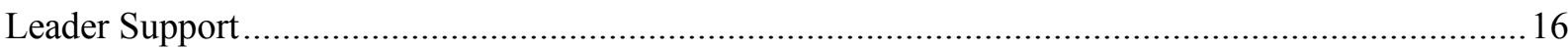



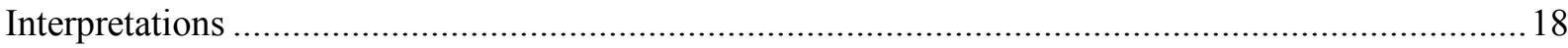

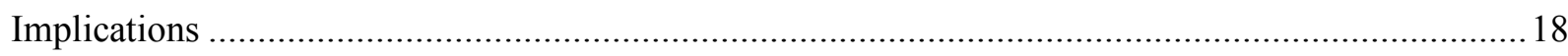

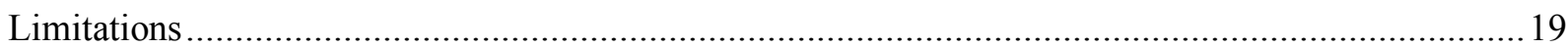

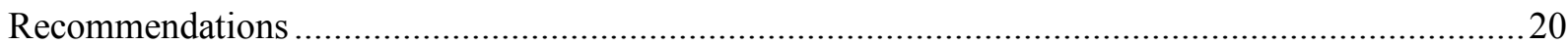

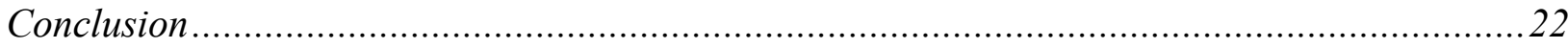

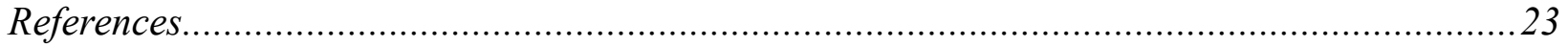




\section{List of Figures}

Figure 1. Bartholomew and Horowitz's two-dimensional model of individual differences in adult

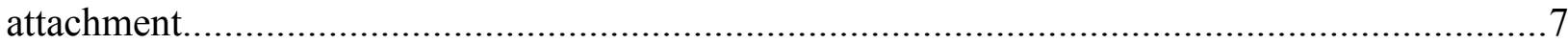




\section{List of Tables}

Table 1. Descriptive Statistics and Correlations.............................................................. 14

Table 2. Coefficients - Attachment avoidance and attachment anxiety to predict frequency of

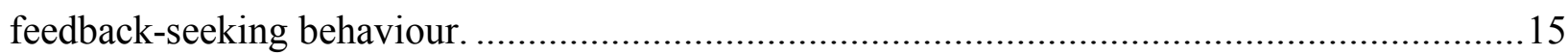

Table 3. Coefficients - Attachment avoidance and attachment anxiety to predict strategy of



Table 4. Coefficients - Attachment avoidance and attachment anxiety to predict type of

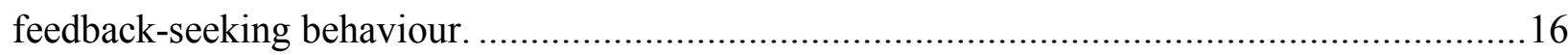
Table 5. Coefficients - The interaction effect of leader support on the relationship between attachment avoidance and anxiety on frequency of feedback-seeking behaviour...................... 16 


\section{Introduction}

Feedback is a powerful tool in the workplace to improve employee engagement and performance, and reduce turnover (Baker, Perreault \& Reid, 2013; Dahling, \& O'Malley, 2011; Harms, 2011; Lyons, 2017; Wu \& Parker, 2017; Zenger \& Folkman, 2014). Research conducted on Google's internal data recognizes the number one key characteristic of great leaders, as identified by employees, is their ability to provide frequent, transparent feedback to their subordinates (Baker et al., 2013; Bryant, 2011). Additionally, proactive feedback practices are rated by employees as more important and influential than leadership experience and technical knowledge (Huang, 2012; Sullivan, 2013; Wu \& Parker, 2017). As such, researchers and industry leaders are seeking new ways to understand and facilitate large-scale, effective feedback practices within organizations (Ashford, Blatt, \& VandeWalle, 2003; Dahling, \& O’Malley, 2011). 


\section{Literature Review}

Feedback

Individual feedback is an effective tool to encourage performance based improvements within organizations. Feedback is defined as the information shared between two individuals regarding the receiver's performance in the accomplishment of work-related tasks (Baker et al., 2013; Lyons, 2017; Richards \& Schat, 2011). It is used to inform the receiver of desirable behaviour and to "determine the correctness and adequacy of behaviours for attaining valued end states" (Ashford, 1986, p. 466). This constructive information is often framed in the workplace as positive reinforcement or corrective guidance.

Feedback is not only beneficial for the receiver, it also has the potential to positively influence the organization and business as a whole (Baker et al., 2013; Beenen, Pichler \& Levy, 2016). Not surprisingly, considerable evidence shows that companies who embrace effective feedback practices have a greater competitive advantage and experience more success and sustainability in the market (Baker et al., 2013; Zenger \& Folkman, 2014). Despite this awareness, however, research shows that employees report not receiving feedback from their superiors as often as they would like. According to Zenger and Folkman (2014), 65\% of employees would like to receive more feedback from their managers, and $98 \%$ of employees disengage with their workplace when managers give little or no feedback. This discrepancy in desired and actual frequency of feedback sharing indicates a critical area of opportunity for employees and organizations to improve their performance (Chun, Choi \& Moon, 2014).

There are several barriers managers face when providing adequate feedback to subordinates such as lacking the skill to effectively communicate feedback and lacking selfconfidence as a leader to engage in these conversations (Zenger \& Folkman, 2014). However, there is a growing body of literature that suggests individual and relational differences may impact one's willingness to seek and offer feedback in the workplace (Ashford et al., 2003; Zenger \& Folkman, 2014). It is known that there are substantial benefits to having feedbackfriendly organizations (Baker et al., 2013). This understanding is relatively new to the past decade, however, companies are beginning to transform their processes and cultures as a result of new best practices and learning (Baker et al., 2013; Tsai, 2011).

Traditionally, feedback processes within organizations were formal (Pearce \& Porter, 1986). These formal feedback processes are structured, require preparation and are scheduled in 
advance (Cappelli \& Tavis, 2016). They also consist largely of formal appraisals and top-down information sharing from leader to follower (Pearce \& Porter, 1986). An example of a formal feedback process is an employee's annual performance evaluation. More recently, however, organizations are trending toward more ongoing, informal feedback sharing. Informal feedback is communicated in everyday interactions and lacks the structure of formal feedback (Cappelli \& Tavis, 2016; Baker et al., 2013). Research shows that employees who engage in informal feedback processes on a regular basis perform better, are more engaged and are less likely to seek employment opportunities at other organizations (Dahling \& O’Malley, 2011; Zenger \& Folkman, 2014). The major benefit of informal feedback sharing is that it provides employees with the opportunity to proactively seek the feedback they desire in the workplace at their discretion and preferred frequency (Huang, 2012; Pitkänen \& Lukka, 2011).

Notably, this cultural shift from formal feedback to ongoing, informal feedback within organizations has added an additional responsibility for leaders (Allen, Shockley \& Poteat, 2010; Tuckey, Brewer \& Williamson, 2010). As previously mentioned, many of these individuals find it difficult to initiate these conversations with their subordinates, and even more so when the information being shared is not entirely positive (Zenger \& Folkman, 2014). To minimize the challenges associated with these conversations, organizations may recommend one or both of the following solutions. The first common solution is to improve training for leaders on how to effectively provide feedback to their subordinates (Fonesca \& Murphy, 2017; Zenger \& Folkman, 2014). Much of the advice in this domain focuses on communicating feedback in ways that will increase the likelihood of positive receptivity from the feedback receiver (Hedges, 2015). The second solution is to encourage employees to proactively seek feedback from their managers directly (Huang, 2012). This proactive behaviour initiated by the receiver is generally seen as a positive method of self-improvement and an effective way of growing professionally (Zenger \& Folkman, 2014). There is an important gap in the literature regarding who is most likely to seek feedback from their leaders, and who is more likely to avoid it (and thus, have more or fewer opportunities to develop and engage in their work).

Feedback-Seeking Behaviour

The current research aims to investigate the latter, and increasingly more popular solution to this challenge - proactive employee feedback-seeking behaviour. Feedback-seeking behaviour (FSB) is defined as the process in which the receiver actively seeks to understand "the 
correctness and adequacy of behaviours for attaining valued end states" (Ashford, 1986, p. 466). Ashford (1986) first challenged the traditional understanding that employees are passive recipients in the feedback process. Since then, researchers have identified two distinct methods to actively seek feedback. The first method is inquiry which is a direct investigation of how others perceive and evaluate the receiver's performance (Crommelinck \& Anseel, 2013; Karakowsky, Podolsky \& Elangovan, 2019). The second method is observation which includes the monitoring of environmental cues and responses to best infer others' perspectives of oneself (Chun et al., 2014; Huang, 2012). For the purposes of this literature review, the style of FSB under investigation is feedback inquiry (Ashford et al., 2003; Wu \& Parker, 2017). Later in this paper, the individual and contextual factors that present perceived risks for recipients seeking feedback will be discussed.

Since Ashford's seminal research in 1986, the literature on proactive workplace behaviour has continued to contribute to research on feedback inquiry. Proactive behaviour is defined as "self-initiated and future-oriented action that aims to change and improve the situation or oneself' (Parker, Williams \& Turner, 2006, p. 636). Exploring feedback inquiry as a proactive individual behaviour in the workplace is an extremely new approach to feedback research and it allows researchers to consider the individual differences at play in this process (Karakowsky et al., 2019; Lanciano \& Zammuner, 2014).

This paper will further explore the individual factors (of the subordinate employee) and target factors (of the manager) that may influence the feedback-seeking process. Specific individual factors that have been identified as important influencers of FSB include, but are not limited to: feedback orientation, learning goal orientation, tolerance for ambiguity, and selfesteem (Karakowsky et al., 2019; Tucker, Brewer \& Williamson, 2010). Specific target factors include, but are not limited to: relationship quality, leadership style, availability/accessibility, support, and mood (Tsai, 2011). Although feedback-seeking research has existed for over 30 years, a lack of consensus regarding what factors influence frequency of feedback-seeking behaviour still exists.

Within the feedback-seeking literature, however, there are three general understandings that exist. First, the quality of a supervisor-subordinate relationship is associated with different feedback-seeking behaviours. The research on this topic uses Leader Member Exchange Theory to demonstrate that the quality of relationship between the manager and subordinate is related to 
the type of feedback subordinates seek, such that there is a positive relationship between high quality relationships and negative feedback-seeking behaviour (Crommelinck \& Anseel, 2013; Dienesch \& Liden, 1986). Followers report a sense of security in their relationship and trust that their leaders will provide the appropriate guidance without fear of extreme punishment (Chun et al., 2014). Second, there is a significant relationship between the perception of leadership style and feedback-seeking behaviour (Stoker, Grutterink, \& Kolk, 2012), such that there is a positive relationship between the perception of transformational leadership style and feedback-seeking intentions (Levy, Cober, \& Miller, 2006; Stoker et al., 2012). Finally, feedback seeking behaviour can be measured through different perspectives such as frequency and motivation (Ashford, 1986). Recent literature has paid considerably more attention to the frequency of FSB and the most popular measure is Ashford's original feedback-seeking behaviour scale (Ashford, 1986; Crommelinck \& Anseel, 2013).

In addition to theories of social exchange such as Leader-Member Exchange Theory, Attachment Theory is an increasingly more popular framework being applied to relationshiporiented management research (Dienesch \& Liden, 1986). Given the highly relational nature of work, Attachment Theory provides a strong foundation for understanding how subordinate employees approach relationships and thus, behave in the workplace (Harms, 2011).

Management research that leverages Attachment Theory is based on the common understanding that there are many threats in the workplace and employees must self-manage their emotions, fears, and anxieties to achieve their goals (Bretherton, 1992; Yip, Black \& Walker, 1992). Over the next several pages, Attachment Theory will be explored in terms of its origin, evolution, and strong application in adult working relationships.

Attachment Theory

Attachment Theory was first originated in 1969 by an evolutionary psychology researcher, John Bowlby (Bowlby, 1982). According to Attachment Theory, each person develops their innate psychological attachment style based on early caregiving experiences. This attachment style shapes the way individuals mentally represent the self and relationships (Bowlby, 1982; Bretherton, 1992). Based on these early caregiving experiences, attachment styles are developed to navigate the social world and provide motivation to seek and assure proximity to supportive others (attachment figures) in times of need (Bowlby, 1982; Bretherton, 1992). Generally speaking, attachment styles remain fairly stable and continue to reflect internal 
working models of the self, others and relationships throughout a lifetime (Bretherton, 1992; Gillath, Selcuk \& Shaver, 2008; Richards \& Schat, 2011;). However, research also shows that individual attachment style can become more stable over time through repetitive priming with a secure attachment figure whereby they offer closeness and security to the individual in times of need (Bartholomew, 2009; Gillath, Selcuk \& Shaver, 2008).

The original experiments on Attachment Theory were conducted by John Bowlby and Mary Ainsworth (Bowbly, 1982; Bretherton, 1992; Fraley, 2012). Ainsworth conducted the Strange Situation Experiment whereby children and their primary caregivers were analyzed (Bretherton, 1992). This study found that infants develop different strategies to regulate their emotions and maintain a sense of security based on their caregiving environments (Fraley, 2012). As a result, Bowlby and Ainsworth were two of the first researchers to empirically demonstrate that one of the most critical functions of attachment figures (i.e., parents) is to provide a secure caregiving environment (also named 'secure base') for infants to explore and confidently develop (Allen, Shockley, \& Poteat, 2010; Bowlby, 1982; Bretherton, 1992; Harms, 2011). For securely attached individuals, this means that in times of uncertainty, danger or risk, their primary caregiver is their reliable haven (Bretherton, 1992). For those with insecure attachment, it is believed that this support is unreliable and/or inconsistent (Bretherton, 1992; Simmons, Gooty, Nelson \& Little, 2009). Therefore, a major component of attachment theory states that people innately seek the maintenance of proximity to their secure base (Bowlby, 1982; Bretherton, 1992).

Specifically, when the attachment figure is available and responsive to the infant's needs, the infant learns to regulate their emotions internally and develop a sense of security in close relationships: a secure attachment style (Bowlby, 1982). These secure infants have positive mental models of self and others, which results in the development of an internal secure base (Allen, Shockley, \& Poteat, 2010; Bretherton, 1992; Harms, 2011). Infants who experience the absence or unresponsiveness of the attachment figure lack a secure caregiving environment and therefore cannot develop an internal secure base (Fraley, 2012). As such, these infants adopt alternative strategies to maintain a sense of security and soothe their emotions. Insecure attachment style is measured on two dimensions: anxiety about abandonment and avoidance of intimacy (Bretherton, 1992; Simmons et al., 2009). 
The most well regarded and popular measure for determining one's attachment style was developed by Bartholomew and Horowitz in 1991. This model of adult attachment is a twodimensional model that clearly differentiates anxiety and avoidance (Bretherton, 1992). This method combines one measure for the Model of Self and one measure for the Model of Others (relationships). The Model of Self ranges from low anxiety to high anxiety and the Model of Other ranges from low avoidance to high avoidance (Bretherton, 1992). As such, the four attachment styles are secure (low avoidance, low anxiety), preoccupied (low avoidance, high anxiety), dismissing-avoidant (high avoidance, low anxiety), and fearful-avoidant (high avoidance, high anxiety).

Figure 1. Bartholomew and Horowitz's two-dimensional model of individual differences in adult attachment.

Low Avoidance

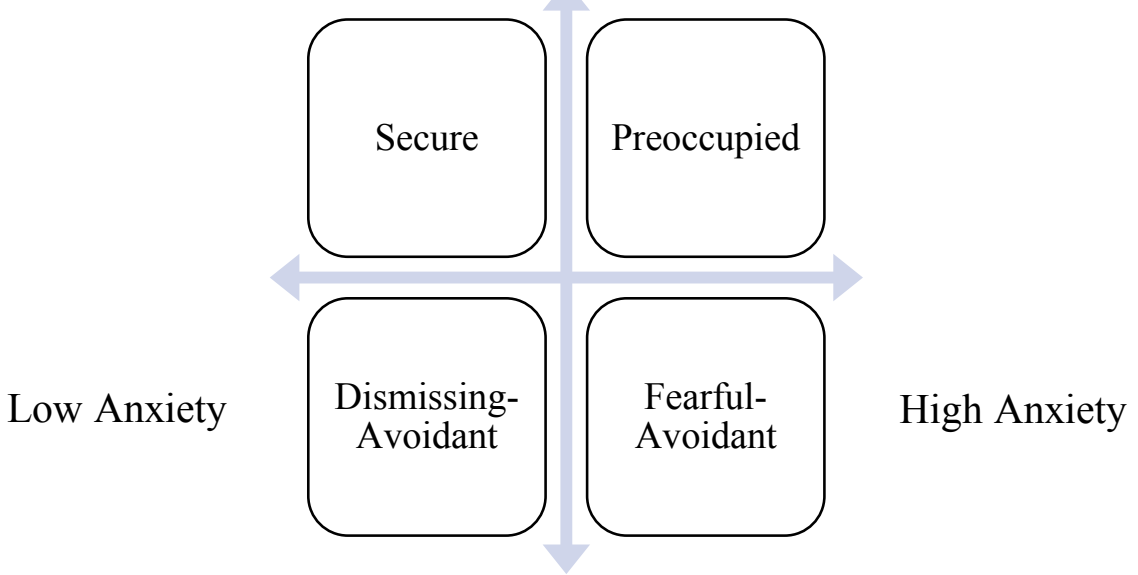

High Avoidance

Traditionally, Attachment Theory was established as a framework for understanding internal working models of interpersonal and emotional experiences, particularly between children and their primary caregivers (Bowlby, 1982). Researchers then discovered that attachment style is relatively stable from childhood to adulthood (Fraley, 2012). Since, Attachment Theory has been extended profusely to investigate other significant adult relationships such as romantic and workplace relationships (Harms, 2011; Richards \& Schat, 2011; Ronen \& Mikulincer, 2009). Given the relational nature of work, management researchers 
have clearly identified a leader-follower dynamic in the workplace that is highly comparable to that of the child and parent- the manager and subordinate employee dyad (Ronen \& Mikulincer, 2010; Simmons et al., 2009; Wu, Parker \& de Jong, 2014; Yip, Ehrhardt, Black \& Walker, 2018).

Attachment Theory in the Workplace

The attachment theory research is generally consistent in showing that adults with different working models of attachment are predisposed to think, feel and behave differently in their relationships at work (Collins, 1996). Bartholomew and Horowitz's model of attachment (Figure 1) can be used to categorize the attachment styles of adults such that they fall into 1 of 4 protoypes: secure, preoccupied, avoidant-dismissive, and avoidant fearful. Adults low in attachment anxiety and attachment avoidance (secure) assess their relationships in the workplace as positive and have few work-related fears (Harms, 2011). They are relatively confident in exploring opportunities and interpersonal relationships. Adults high in attachment anxiety and low in attachment avoidance (preoccupied) have a strong interest in maintaining proximity to their leader and will experience substantial anxiety regarding their performance and relationships at work (Harms, 2011). As such, they seek close proximity to their leaders, and performance is driven by a desire to obtain acceptance and admiration by others (usually their leader). Then, adults low in attachment anxiety and high in avoidance (avoidant-dismissive) report lower levels of stress but also neglect social interactions and avoid close working relationship with colleagues (Harms, 2011). These individuals are perceived by others as reserved and aloof. Finally, adults who are high in attachment anxiety and attachment avoidance (avoidant-fearful) frequent between withdrawing and approaching behaviours (Bretherton, 1992). The message to others is often "come here and go away" (Shorey, 2015).

In the past decade, practitioners have continued to build on theories of human relations to leverage internal human capital by developing coaching environments and encouraging high quality employee relationships (Dahling, \& O’Malley, 2011; Gregory \& Levy, 2012; Stoker et al., 2012). Despite companies understanding the importance of being human-centric in their approach to business, it is only recently that they are investing more time in developing best practices regarding the manager-employee relationship and leveraging it to drive business performance (Fonesca \& Murphy, 2017; Hedges, 2015; Lyons, 2017). As a result, very recent 
research on attachment and workplace performance is conducted with dyads samples, including managers and their subordinate employees (Wu \& Parker, 2017).

In addition to the notion of proximity, another critical component of Attachment Theory is the leader's role in providing a secure base for their follower to explore (Fraley, 2012; Frazier, Gooty, Little \& Nelson, 2015). Early research suggested that infants demonstrate more exploratory behaviour and are more confident engaging in proactive behaviour when their caregiving environment was secure (Bretherton, 1992). Other researchers demonstrated that the availability of an attachment figure is critical for a follower to engage in exploration (Sorce \& Emde, 1981). This exploratory behaviour in children may look like their ability to play well with other children, share toys, and explore unfamiliar areas in the room (Bretherton, 1992; Sorce \& Emde, 1981). Based on this early research, Wu and Parker (2017) suggested that it is necessary for adult leaders to also provide a secure base for followers to engage in proactive behaviour in the workplace. Despite attachment style being understood as a fairly stable individual trait, research shows that secure priming with a workplace attachment figure is associated with more positive and secure follower behaviour (Beenen et al., 2016; Frazier et al., 2015).

This secure-base support provides safety and reassurance to the follower that they may explore their environment with unconditional support (Beenen et al., 2016). Wu and Parker (2017) posited that leader secure-base support consists of the following three components: availability (of a leader's time and support), encouragement (to grow and be challenged), and non-interference (to delegate and trust with the delivery of work). If all these components are fulfilled consistently and over time, the follower should have the foundation to develop and behave more securely (i.e., seek less reassurance and/or distance). However, the relationship between attachment style and FSB, and the moderating effect of leader secure-base support has not yet been explored.

Leader-Member Exchange Theory (LMX) is an alternative theory and framework applied to organizational research to more thoroughly understand the leader-follower relationship (Lam, Peng, Wong \& Lau, 2015). Notably, however, the theoretical base of LMX theory is the concept of a "developed" or "negotiated" relationship, such that it is the role of the leader to modify their behaviour and support to suit the needs of their follower (Dienesch \& Liden, 1986). This study's approach is different in that it focuses on the follower's pre-disposition toward relationships and providing support that is directly related to soothing the follower's attachment anxieties/fears in 
times of need. This study aims to provide an additional lens for relationship-oriented management research (and not discount) the existing literature on LMX, attachment, and feedback-seeking behaviour.

Based on the research reviewed, a critical gap in the literature has been identified. There is very little known on the relationship between attachment and frequency of feedback-seeking behaviour. The impact of this specific individual difference on feedback-inquiry must be considered if organizations are trying to leverage their human capital to improve performance and engagement in the workplace, and reduce turnover (Lanciano \& Zammuner, 2014). Then, the leaders' roles in this process must be further investigated to build the foundation and environment for employees to seek feedback more appropriately. Based on the tenants of Attachment Theory, this encouragement to explore and engage in proactive behaviour may be moderated by the leader's ability to provide secure-base support for their employees (Wu \& Parker, 2017).

Further, in an exploratory fashion, I also examine strategy and type of feedback-seeking behaviour. Strategy of feedback-seeking is interesting to consider because, as previously mentioned, this study is primarily interested in feedback inquiry and the direct investigation of information seeking (Wu, Parker \& de Jong, 2014). The scale used in this study investigates whether an individual seeks feedback through direct inquiry or indirect monitoring (Ashford, 1986). As a result, the findings of this exploratory analysis may add value and provide further insight into how attachment styles influence strategy of feedback-seeking behaviour. The type of feedback-seeking behaviour was also analyzed in an exploratory fashion because recent literature suggests that anxious individuals may seek different feedback than avoidant individuals. Hepper and Carnelley (2009) found that anxious individuals seek more positive relationship-oriented feedback (to gain reassurance and proximity to leader) and avoidant individuals seek more critical task-related feedback (to maintain relational distance and improve performance). Again, this insight may provide deeper insight into this study's purpose of better understanding the extent to which attachment style influences feedback-seeking behaviour. 
Hypotheses

Individuals with high attachment anxiety have a strong need for proximity to their leader and reassurance regarding their relationship and performance. Preoccupied individuals are absorbed with thinking about the quality of their relationships and feel a strong need for close proximity to others (Bretherton, 1992). They generally have a negative view of self, leading them to engage in behaviours that provide external validation, such as feedback-seeking and reassurance.

H1 A: There is a positive relationship between attachment anxiety and frequency of feedback-seeking behaviour.

Individuals with high attachment avoidance avoid close working relationships with their colleagues. They are not likely to seek out approval or worry about their workplace relationships. They may struggle with the maintenance of positive relationships, and put achievement ahead of relationships.

$H 1$ B: There is a negative relationship between attachment avoidance and frequency of feedback-seeking behaviour.

Individuals with high attachment anxiety seek proximity to their leader and are hypervigilant to threat cues such as disapproval. They seek signs of reassurance and acceptance. When leaders provide secure-base support, these individuals require less reassurance and closeness.

H2 A: Leader secure-base support moderates the relationship between attachment anxiety and frequency of feedback-seeking behaviour, such that the positive relationship between attachment anxiety and frequency of feedback-seeking behaviour is weaker at higher levels of leader secure-base support.

Individuals with high attachment avoidance are not comfortable with close working relationships and do not engage in behaviours that increase closeness to others. Secure base support allows these individuals to become more comfortable and secure in their relationship over time.

H2 B: Leader secure-base support moderates the relationship between attachment avoidance and frequency of feedback-seeking behaviour, such that the negative relationship between attachment avoidance and frequency of feedback-seeking behaviour will be weaker at higher levels of leader secure-base support. 


\section{Methodology}

Participants

Participant groups consisted of one manager and one of their subordinate employees. This dyad was analyzed as one data point $(n=18)$. Participants' ages ranged from 18 to 64 years with $75 \%$ of participants falling between 25 and 54 years. Additionally, $73 \%$ of participants identified as female and $27 \%$ identified as male. Finally, $77 \%$ of participants reported having a Bachelor's or Master's degree, and 77\% of participants report having worked with their pair for 3 months -3 years.

Materials

An online survey was created using Google Forms for each member of the dyad: 1) Survey for Managers, and 2) Survey for Subordinate Employees. Each survey took no more than 10 minutes to complete.

Procedure

To recruit participants, I emailed my professional network because it was critical that participants were employed by an organization. Participants responded to the recruitment email if they and their manager/subordinate wanted to participate. I sent the consent form by email to each member of the dyad to review and sign. My intent was to minimize the pressure each member of the dyad experienced while considering participation in the study and provide them the opportunity to decline participation without penalty. Once I received the signed consent forms, I sent the separate online surveys to each participant. The survey was created and shared via Google Forms. Participants were entered into a raffle to win a \$100 Starbucks gift card as incentive to participate.

Survey - Subordinate Employees

The survey for subordinate employees measured 2 dimensions: attachment (what is their attachment style?) and leader secure-base support (does their leader provide a secure base?).

To measure attachment, the Experiences in Close Relationships (Short) Scale was used (Wei et al., 2007). The language in this original scale is specific to romantic relationships so it was adapted for the context of this study. For example, the statement "I try to avoid getting too close to my romantic partner" was replaced with "I try to avoid getting too close to my manager". In the management literature, this is a popular application and modification of the scale (Ronen \& Mikulincer, 2012; Wei et al., 2007). Participants rated each item on a 5-point scale, anchored by 
strongly agree and strongly agree. Researchers found that the 12-item ECR-S scale provides a reliable and valid measure of adult attachment and the psychometric properties of the short version of the scale are comparable or equivalent to the ECR scale (Fraley, 2012; Wei et al., 2007). Cronbach's alpha for the avoidance subscale was 0.62 and for the anxiety scale was 0.60.

To measure Leader Secure-Base Support, a scale developed by Wu and Parker (2017) was used. Wu \& Parker (2017) used existing leadership items and adapted items from an existing secure-base support scale when necessary. This construct was measured on three dimensions: leader availability for support, leader encouragement of growth, and leader non-interference (from delegation). For the purposes of this study, and as aligned with Wu and Parker's (2017) use of the scale, the three dimensions were collapsed rather than examined separately. This scaled demonstrated reliability with Chronbach's alpha reported as 0.77 . Items used a 5-point response format anchored by strongly agree and strongly agree. Sample items for availability, encouragement, and non-interference include "My supervisor is sympathetic and supportive when I am worried or upset about something", "My supervisor encourages me to live up to my potential", and "My supervisor encourages me to determine for myself the best way to carry out an assignment or accomplish an objective", respectively (Wu and Parker, 2017).

Survey - Managers

The survey for managers measured feedback seeking behaviour (of subordinate employees). Wu and Parker (2014) recently used an adapted version of Ashford's (1986) scale, leveraging the following 3 measures: frequency of inquiry about performance behaviours, strategy of feedback-seeking behaviour (direct inquiry or observation) and type of feedback (positive or negative). Items used a 5-point response format anchored by "not very characteristic" and "very characteristic" (of this employee). The frequency subscale consisted of 3 items $(\alpha=0.70)$, the strategy subscale consisted of 8 items $(\alpha=0.83)$, and the type subscale consisted of 4 items $(\alpha=0.68)$. One sample item from this frequency of feedback-seeking behaviour scale includes "How frequently does this employee seek feedback from you about his/her performance?". 


\section{Results}

The results section does not report binary measures as the analytical approach due to limited data. Even though the literature often divides individuals into quadrants (Bretherton, 1992), given the limited data points and to increase the power of analysis, this study analyses the raw scores for attachment anxiety and avoidance.

Table 1. Descriptive Statistics and Correlations

$\begin{array}{lllllll}\text { Mean } \quad \text { Std. Dev } \quad 1 . & 2 . & 3 . & 4 . & 5 . & 6 .\end{array}$

$\overline{1 .}$ Avoidance $\quad \overline{2.13}$

Score

2. Anxiety $\quad 2.51 \quad .61 \quad 0.41$

Score

3. Perceived $3.99 \quad 0.54 \quad-0.40 \quad-0.24$

Leader Support

$\begin{array}{llllllll}\text { 4. FS Freq. } & 8.50 & 2.90 & -0.24 & 0.06 & 0.34 & & \\ \text { 5. FS Strategy } & 2.91 & 0.74 & -0.13 & 0.20 & -0.08 & 0.39 & \\ \text { 6. FS Type } & 2.63 & 1.01 & 0.17 & 0.19 & 0.24 & 0.60^{* *} & 0.62^{* *}\end{array}$

$\mathrm{N}=18 .{ }^{* *}$, correlation is significant at the 0.01 level (2-tailed).

The literature suggests that attachment is best modeled with dimensions rather than categories. Researchers argue that classifying people on the basis of their scores necessarily reduces the precision of measurement and lowers the statistical power (Fraley, 2012). Analyzing the two dimensions simultaneously in a regression framework allows the data to be interpreted in a manner that is conceptually aligned with Bartholomew's four attachment prototypes, but also in a way that allows other regions of the two-dimensional space to be accurately represented (Fraley, 2012).

Following such an approach, I tested Hypotheses 1a and b accordingly and the results are reported below.

Frequency of Feedback Seeking

A multiple linear regression was conducted to determine if attachment avoidance and attachment anxiety predicted frequency of employee feedback-seeking behaviour. 
Table 2. Coefficients - Attachment avoidance and attachment anxiety to predict frequency of feedback-seeking behaviour.

\begin{tabular}{|c|c|c|c|c|c|c|c|}
\hline & \multicolumn{2}{|c|}{$\begin{array}{c}\text { Unstandardized } \\
\text { Coefficients }\end{array}$} & \multirow{2}{*}{$\begin{array}{c}\text { Standardized } \\
\text { Coefficients }\end{array}$} & \multirow[t]{2}{*}{$\mathrm{t}$} & \multirow[t]{2}{*}{ Sig. } & \multicolumn{2}{|c|}{$95.0 \%$ Confidence Interval for B } \\
\hline & $\mathrm{B}$ & Std. Error & & & & Lower Bound & Upper Bound \\
\hline (Constant) & 9.76 & 3.46 & & 2.82 & .28 & 2.37 & 17.14 \\
\hline AvgAttAnx & 0.89 & 1.28 & .19 & .69 & .50 & -1.86 & 1.39 \\
\hline AvgAttAvoid & -1.64 & 1.42 & -.31 & -1.53 & .27 & -4.67 & 3.63 \\
\hline
\end{tabular}

Using the enter method, the results from this multiple regression analysis found that attachment avoidance and attachment anxiety do not have a significant impact on frequency of feedback-seeking, $\left[F(2,15)=0.69, p=.52, R^{2}=.09, R^{2}\right.$ Adjusted $\left.=-.04\right]$.

The analysis shows that attachment avoidance did not significantly predict frequency of feedback-seeking $(\beta=-.31, t(17)=-1.53, p=.27)$, and attachment anxiety did not significantly predict frequency of feedback-seeking $(\beta=.19, t(17)=0.69, p=.50)$.

Strategy of feedback-seeking

Next, a multiple linear regression was conducted to determine if attachment avoidance and attachment anxiety predicted strategy of feedback-seeking behaviour.

Table 3. Coefficients - Attachment avoidance and attachment anxiety to predict strategy of feedback-seeking behaviour.

\begin{tabular}{|c|c|c|c|c|c|c|c|}
\hline & \multicolumn{2}{|c|}{$\begin{array}{c}\text { Unstandardized } \\
\text { Coefficients }\end{array}$} & \multirow{2}{*}{$\begin{array}{c}\begin{array}{c}\text { Standardized } \\
\text { Coefficients }\end{array} \\
\text { Beta }\end{array}$} & \multirow[t]{2}{*}{$\mathrm{t}$} & \multirow[t]{2}{*}{ Sig. } & \multicolumn{2}{|c|}{$95.0 \%$ Confidence Interval for B } \\
\hline & $\mathrm{B}$ & Std. Error & & & & Lower Bound & Upper Bound \\
\hline (Constant) & 2.70 & 0.88 & & 3.08 & 0.01 & 0.83 & 4.57 \\
\hline AvgAttAnx & 0.38 & 0.33 & 0.31 & 1.15 & 0.27 & -0.32 & 1.07 \\
\hline AvgAttAvoid & -0.35 & 0.36 & -0.26 & -0.96 & 0.35 & -1.11 & 0.42 \\
\hline
\end{tabular}

Using the enter method, the results from this multiple regression analysis found that attachment avoidance and attachment anxiety do not have a significant impact on strategy of feedback-seeking, $\left[F(2,15)=0.81, p=.46, R^{2}=.10, R^{2}\right.$ Adjusted $\left.=-.02\right]$. 
The analysis shows that attachment avoidance did not significantly predict strategy of feedback-seeking $(\beta=-.26, t(17)=-.96, p=0.35)$, and attachment anxiety also did not significant predict strategy of feedback-seeking $(\beta=.31, t(17)=1.15, p=.27)$. Type of Feedback Seeking

A multiple linear regression was conducted to determine if attachment avoidance and attachment anxiety predicted type of employee feedback-seeking behaviour.

Table 4. Coefficients - Attachment avoidance and attachment anxiety to predict type offeedbackseeking behaviour.

\begin{tabular}{|c|c|c|c|c|c|c|c|}
\hline & \multicolumn{2}{|c|}{$\begin{array}{c}\text { Unstandardized } \\
\text { Coefficients }\end{array}$} & \multirow{2}{*}{$\begin{array}{c}\text { Standardized } \\
\text { Coefficients }\end{array}$} & \multirow[t]{2}{*}{$\mathrm{t}$} & \multirow[t]{2}{*}{ Sig. } & \multicolumn{2}{|c|}{$95.0 \%$ Confidence Interval for B } \\
\hline & $\mathrm{B}$ & Std. Error & & & & Lower Bound & Upper Bound \\
\hline (Constant) & 1.60 & 1.24 & & 1.30 & 0.22 & -1.06 & 4.23 \\
\hline AvgAttAnx & 0.25 & 0.46 & 0.15 & 0.54 & 0.60 & -0.73 & 1.23 \\
\hline AvgAttAvoid & 0.19 & 0.51 & 0.11 & 0.38 & 0.71 & -0.89 & 1.28 \\
\hline
\end{tabular}

Using the enter method, the results from this multiple regression analysis found that attachment avoidance and attachment anxiety do not have a significant impact on type of feedback-seeking, $\left[F(2,15)=.37, p=.70, R^{2}=.05, R^{2}\right.$ Adjusted $\left.=-.08\right]$.

The analysis shows that attachment avoidance did not significantly predict the type of feedback-seeking $(\beta=.11 t(17)=.38, p=.71)$, and attachment anxiety also did not significant predict the type of feedback-seeking $(\beta=.15, t(17)=.54, p=.60)$.

\section{Leader Support}

Then, I tested Hypotheses $2 \mathrm{a}$ and $\mathrm{b}$ and the results are reported below.

Table 5. Coefficients - The interaction effect of leader support on the relationship between attachment avoidance and anxiety on frequency of feedback-seeking behaviour.

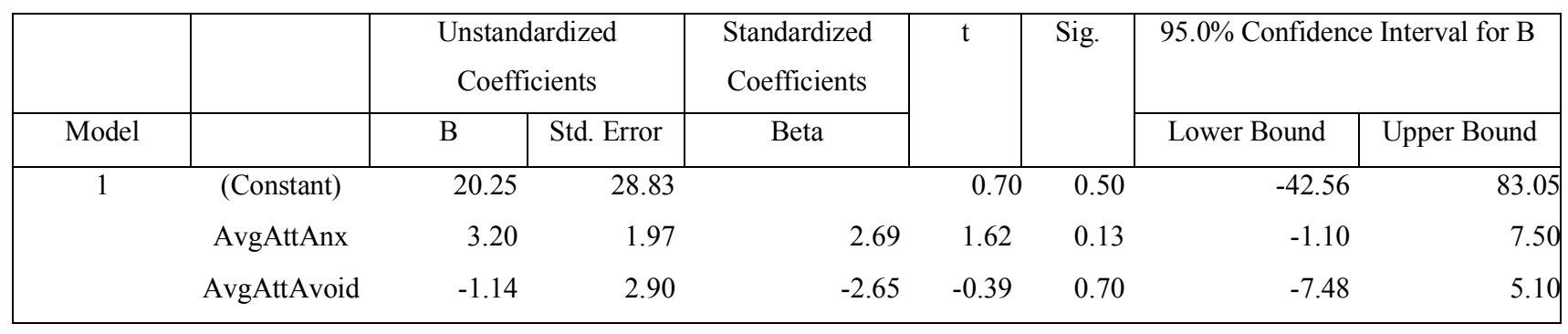


The results from this multiple regression with interaction analysis found that leader secure-base support does not significantly moderate the relationship between attachment avoidance and attachment anxiety and frequency of feedback-seeking behaviour, $[F(5,12)=$ $\left.1.13, p=.40, R^{2}=0.32, R_{\text {Adjusted }}^{2}=0.04\right]$.

The analysis shows that the interaction of leader support on attachment avoidance did not significantly predict frequency of feedback-seeking behaviour $(\beta=-2.65 t(17)=-0.39, p=.70)$, and the interaction on attachment anxiety also did not significantly predict frequency of feedback-seeking behaviour $(\beta=2.69, t(17)=1.62, p=0.13)$.

Taken together, the results presented above failed to provide support to $\mathrm{H} 2 \mathrm{a}, \mathrm{b}$. 


\section{Discussion}

\section{Interpretations}

As per the results, attachment avoidance is not significantly related to frequency of feedback-seeking behaviour. Also, Attachment Anxiety is not significantly related to frequency of feedback-seeking behaviour. Finally, leader secure-base support does not significantly moderate the relationship between attachment anxiety and attachment avoidance and frequency of feedback-seeking behaviour.

The earlier research in this field highlights the importance of more thoroughly understanding the impact of attachment styles on workplace behaviour and feedback-seeking behaviour (Harms, 2011; Ronen \& Mukulincer, 2009; Simmons et al., 2009; Yip et al., 2018). The results of this study show the correlations are trending in the hypothesized direction but nonsignificant. Given that the results are not significant, further research should be conducted on the topic to more thoroughly understand the mechanisms at play.

Implications

This increasingly more common transformation of organizations to shift toward continuous, ongoing feedback sharing (versus formal performance evaluations) impacts the way managers lead their subordinates (Dahling \& O’Malley, 2011; Zenger \& Folkman, 2014). They are required to be more aware of employees who take initiative in their professional development and who proactively seek feedback. Feedback inquiry is becoming an increasingly more valued behaviour of employees and managers are becoming more encouraged to identify and respond supportively to it (Baker et al., 2013; Zenger \& Folkman, 2014). Notably, however, given the nature of these individual differences, it is important for managers to fully understand the implications of their employees' behaviour and make informed future decisions accordingly Lanciano \& Zammuner, 2014).

The results of this study demonstrate a non-significant relationship between anxious attachment and avoidant attachment and frequency of feedback-seeking behaviour. Notably, however, if the hypotheses had been supported, this would have suggested that managers might benefit from being more sensitive to individual differences in feedback-seeking behaviour and aware of the types of employees who engage in such behaviours, and why. Further, it would have also suggested that it would be important for managers to consider other characteristics of 
their subordinates' feedback-seeking behaviour, (rather than frequency), such as type or strategy of feedback-seeking.

Another possible implication is that perhaps not all employees in this study view their manager as an attachment figure. Other potentially confounding variables should be explored and/or controlled for such as tenure working together and amount of quality time spent together.

The non-significant results could also suggest that attachment anxiety and avoidance do not place employees at any particular advantage or disadvantage in the workplace. If hypothesis 1a had been supported and the results demonstrated a positive relationship between attachment anxiety and frequency of feedback seeking behaviour, anxious employees may have been at a particular advantage for career development because of their more frequent feedback-seeking. Oppositely, if hypothesis $1 \mathrm{~b}$ had been supported and the results demonstrated a negative relationship between attachment avoidance and frequency of feedback seeking behaviour, avoidant employees may have been at a particular disadvantage for career development as their less frequent feedback-seeking is perceived as aloof and indicative as less interest in professional development or career advancement (Zenger \& Folkman, 2014). Further research should investigate this topic further to determine whether the manager's perception of a subordinate's frequency of feedback-seeking behaviour can help or harm the subordinate's professional development.

Finally, there was no significant interaction effect of leader secure-base support on attachment anxiety and attachment avoidance and frequency of feedback-seeking behaviour. Further research should investigate whether this construct has a significant effect in other contexts, or whether there are other influencing variables such as Leader Member Exchange (Dienesch \& Liden, 1986).

\section{Limitations}

There are three critical limitations to consider. First, the sample is considerably small. There were 18 dyads (36 participants) in the study which is insufficient sample size for statistical significance/measurement. This could explain why correlation occurred between the variables but did not reach significance. As a result, the study is vulnerable to type II error whereby the null hypothesis is wrongly accepted. Second, this study is vulnerable to selection bias. Snowball sampling does not result in true random sampling of participants. Many of the participants were in the experimenter's immediate and extended professional network. Finally, self-selection bias 
is a limitation of this study. Given the nature of the study, particular types of individuals may have been more likely to participate (or not). For example, individuals with Avoidant Attachment may have been less likely to participate in the study because it required them to engage their managers/subordinates in the study and thus, encourage their partner to reflect on their working relationship - avoiding closeness/proximity with their attachment figure is characteristic of Avoidant individuals. Further, it may be likely that those deemed "Avoidant" in this study are not normally distributed on this scale. Those who were analyzed as "high avoidant" may not be representative of the truly avoidant individuals in the population because of self-selection bias. Likely, individuals with Anxious Attachment may have been less likely to participate in this study due to the worries they may have regarding the relationship with their attachment figure. Further, it may be true that these individuals are not consciously aware of their attachment style and thus are not actively aware of their decision to participate (or not). It would be characteristic of an Anxious individual to be overly concerned with the impact of such participation on their relationship and manager's perception of them. As previously mentioned, the study design tried to mitigate this risk by stating in the recruitment email and consent form that neither member of the dyad would have access to each other's responses (confidentiality) and it would not impact their professional relationship, however, it is still in the reader's discretion whether they want to voluntarily participate.

Recommendations

Future research should aim to replicate this study while making appropriate modifications to address the previously mentioned limitations. These modifications may include recruiting more participants and also utilizing a different recruitment method to encourage a more diverse and representative sample to participate. Future researchers could modify the study so that it does not require dyads to participate. The methodology could be modified so that the subordinate employee would self-report their feedback-seeking behaviour (versus the manager reporting this information). This should encourage more individuals to participate in the study. In addition to replicating the aims of the study, there are also other relevant and important areas of research that require further investigation. Currently, very little is known about how leaders can encourage employees to make behavioural modifications regarding feedback-seeking behaviour. Organizations that want to thrive and maintain their competitive advantage need to increasingly consider elevating their human capital. It is important to more thoroughly understand who is 
likely to seek constructive feedback (and therefore, have clear avenues for development) and who is not likely to do so (Yip et al., 2018). Managers will be more effective people leaders when they understand their employees' needs, desires and motivation (Dienesch \& Liden, 1986; Zenger \& Folkman, 2014). Leader-Member Exchange Theory (LMX) suggests that high quality workplace relationships require managers to approach relationships with their subordinates individually and tailor their management style to suit the subordinate's needs (Dienesch \& Liden, 1986). Notably, however, future research should continue to build on the existing LMX research to provide an additional, specialized lens on the predispositions of subordinate employees and other trait qualities that influence behaviour and the ability to build effective workplace relationships. LMX emphasizes the process of social exchange rather than this study's unique perspective of the subordinate's attachment. Further, it would be valuable to have the knowledge and ability to differentiate and recognize an employee who is seeking positive feedback for reassurance/proximity versus an employee who is seeking infrequent critical feedback for development purposes - and, as a leader, how to encourage them to seek the most effective feedback for them as individuals. 


\section{Conclusion}

Despite feedback being a popular field of management research, very little attention has been paid to the relationship between individual differences in attachment style and feedbackseeking behaviour. When organizations are feedback-friendly and employees feel safe to explore, challenge each other, and grow, they maintain their competitive edge (Baker et al., 2013). Notably, however, given the very recent shift in organizational leaders encouraging more frequent feedback-seeking behaviour, the assumption is that the individual leader has more influence on pro-active behaviour than the organization itself. As the infamous quote says, "People leave managers, not companies" (Hyacinth, 2017). It is important that more research is conducted to better support each of our employees through these processes. 


\section{References}

Allen, T., Shockley, K., \& Poteat, L. (2010). Protégé anxiety attachment and feedback in mentoring relationships. Journal of Vocational Behavior, 77, 73-80. doi:

10.1016/j.jvb.2010.02.007

Ashford, S. J. (1986). Feedback-seeking in individual adaptation: A resource

perspective. Academy of Management Journal, 29(3), 465-487. doi: 10.2307/256219

Ashford, S., Blatt, R., \& VandeWalle, D. (2003). Reflections on the looking glass: A review of research on feedback-seeking behavior in organizations. Journal of Management, 29(6), 773779. doi: 10.1016/S0149-2063(03)00079-5

Baker, A., Perreault, D., \& Reid, A. (2013). Feedback and organizations: Feedback is good, feedback-friendly culture is better. Canadian Psychology, 54(4), 260-268. doi: $10.1037 / \mathrm{a} 0034691$

Bartholomew, K. (2009). Assessment of individual differences in adult attachment. An International Journal for the Advancement of Psychological Theory, 5(1), 23-67. doi:10.1207/s15327965pli0501_2

Beenen, G., Pichler, S., \& Levy, P. E. (2016). Self-determined feedback seeking: The role of perceived supervisor autonomy support. Human Resource Management, 56(4), 555-569. doi:10.1002/hrm.21787

Bretherton, I. (1992). The origins of attachment theory: John Bowlby and Mary Ainsworth. Developmental Psychology, 28(5), 759-775.

Bryant, A. (2011). Google's quest to build a better boss. The New York Times.

Cappelli, P., \& Tavis, A. (2016). The performance management revolution. In Harvard Business Review. Retrieved from https://hbr.org/2016/10/the-performance-management-revolution Chopik, W. J. (2015). Relational attachment and ethical workplace decisions: The mediating role of emotional burnout. Personality and Individual Differences, 75, 160-164. doi: 0.1016/j.paid.2014.11.007

Chun, J., Choi, B., \& Moon, H. (2014). Subordinates' feedback-seeking behavior in supervisory relationships: A moderated mediation model of supervisor, subordinate, and dyadic characteristics. Journal of Management and Organization, 20(4), 463-484. doi:10.1017/jmo.2014.39 
Dahling, J. J., \& O’Malley, A. L. (2011). Supportive feedback environments can mend broken performance management systems. Industrial and Organizational Psychology, 4, 201-203.

Dienesch, R. M., \& Liden, R. C. (1986). Leader-member exchange model of leadership: A critique and further development. The Academy of Management Review, 11(3), 618-634. doi: 10.5465/amr.1986.4306242

Fonesca, T., \& Murphy, T. (2017) Avoiding the feedback monsters. In Deloitte Insights. Retrieved from https://www2.deloitte.com/us/en/insights/focus/behavioraleconomics/principles-for-delivering-effective-feedback.html

Fraley, C. (2012). Information on the experiences in close relationships-revised (ECR-R) adult attachment questionnaire. In University of Illinois. Retrieved from http://labs.psychology.illinois.edu/ rcfraley/measures/ecrr.htm

Frazier, M. L., Gooty, J., Little, L. M., \& Nelson, D. L. (2015). Employee attachment: implications for supervisor trustworthiness and trust. Journal of Business and Psychology, 30(2), 373-386. doi: 10.1007/s10869-014-9367-4

Gillath, O., Selcuk, E., \& Shaver, P. (2008). Moving toward a secure attachment style: can repeated security priming help? Social and Personality Psychology Compass, 2, 1651-1666. doi: 10.1111/j.1751-9004.2008.00120.x

Gregory, J. B., \& Levy, P. E. (2012). Employee feedback orientation: Implications for effective coaching relationships. Coaching: An International Journal of Theory, Research and Practice, 5, 86 -99. doi:10.1080/17521882.2012.691888

Harms, P. D. (2011). Adult attachment in the workplace. Human Resource Management Review, 21, 285-296. doi:10.1016/j.hrmr.2010.10.006

Hedges, K. (2015). How to give concise positive feedback. In Forbes. Retrieved from https:/www.forbes.com/sites/work-in-progress/2015/10/07/how-to-give-concise-positivefeedback/\#9f4b4b71ceaf

Hepper, E., \& Carnelley, K. B. (2009). Adult attachment and feedback-seeking patterns in relationships and work. European Journal of Social Psychology, 40(3), 448-464. doi:10.1002/ejsp.636

Huang, A. (2012). Be proactive as empowered? The role of trust in one's supervisor in psychological empowerment, feedback seeking, and job performance. Journal of Applied Social Psychlogy, 42, E103-E127. doi:10.1111/j.1559-1816.2012.01019.x 
Hyacinth, B. (2017). Employees don't leave companies, they leave managers. In LinkedIn.

Retrieved from https://www.linkedin.com/pulse/employees-dont-leave-companies-managersbrigette-hyacinth

Karakowsky, L., Podolsky, M., \& Elangovan, A. R. (2019). Signaling trustworthiness: The effect of leader humor on feedback-seeking behavior. The Journal of Social Psychology. doi:10.1080/00224545.2019.1620161

Lanciano, T., \& Zammuner, V. L. (2014). Individual differences in work-related well-being: The role of attachment style. Europe's Journal of Psychology, 10(4), 694-711. doi:10.5964/ejop.v10i4.814

Levy, P. E., Cober, R. T., \& Miller, T. (2006). The effect of transformational and transactional leadership perceptions on feedback-seeking intentions. Journal of Applied Social Psychlogy, 32(8), 1703-1720. doi:10.1111/j.1559-1816.2002.tb02771.x

Lyons, R. (2017, July). Feedback: You need to lead it. In Forbes. Retrieved from https://www.forbes.com/sites/richlyons/2017/07/10/feedback-you-need-to-leadit/\#1b9b4be74a35

Pearce, J. L., \& Porter, L. W. (1986). Employee responses to formal performance appraisal feedback. Journal of Applied Psychology, 71(2), 211-218. doi:10.1037/0021-9010.71.2.211

Pitkänen, H., \& Lukka, K. (2010). Formal and informal feedback in management accounting. Chartered Institute of Management Accountants, 6(14).

Richards, D., \& Schat, A. C. (2011). Attachment at (not to) work: Applying attachment theory to explain individual behavior in organizations. Journal of Applied Psychology, 96(1), 169-182. doi:10.1037/a0020372

Ronen, S., \& Mikulincer, M. (2009). Attachment orientations and job burnout: The mediating role of team cohesion and organizational fairness. Journal of Social and Personal Relationships, 26, 549-567. doi:10.1177/0265407509347930

Ronen, S., \& Mikulincer, M. (2010). Predicting employee's satisfaction and burnout from managers' attachment and caregiving. Paper presented at the Annual Meeting of the Academy of Management, Montreal, 2010. Montreal, QC, Canada.

Ronen, S., \& Mikulincer, M. (2012). Predicting employees' satisfaction and burnout from managers' attachment and caregiving orientations. European Journal of Work and Organizational Psychology, 21(6), 828-849. doi:10.1080/1359432X.2011.595561 
Scrima, F., Di Stefano, G., Guarnaccia, C., \& Lorito, L. (2015). The impact of adult attachment style on organizational commitment and adult attachment in the workplace. Personality and Individual Differences, 86, 432-437. doi:10.1016/j.paid.2015.07.013

Shorey, H. (2015). Come here, go away: The dynamics of fearful attachment. In Psychology Today. Retrieved from https://www.psychologytoday.com/ca/blog/the-freedomchange/201505/come-here-go-away-the-dynamics-fearful-attachment

Simmons, B., Gooty, J., Nelson, D., \& Little, L. (2009). Secure attachment: Implications for hope, trust, burnout, and performance. Journal of Organizational Behavior, 30, 233-247.doi: 10.1002/job.585

Stoker, J. I., Grutterink, H., \& Kolk, N. J. (2012). Do transformational CEOs always make the difference? The role of TMT feedback seeking behavior. The Leadership Quarterly, 23(3), 582-5921. doi:10.1016/j.leaqua.2011.12.009

Tuckey, M., Brewer, N., \& Williamson, P. (2010). The influence of motives and goal orientation on feedback seeking. Journal of Occupational and Organizational Psychology, 75, 195-216. doi:10.1348/09631790260098677

Wu, C., \& Parker, S. K. (2017). The role of leader support in facilitating proactive work behaviour: a perspective from attachment theory. Journal of Management, 43(4), 1025-1049. doi:10.1177/0149206314544745

Wu, C., Parker, S. K., \& de Jong, J. P. (2014). Feedback seeking from peers: A positive strategy for insecurely attached team-workers. Human Relations, 67(4), 441-464. doi:10.1177/0018726713496124

Yip, J., Ehrhardt, K., Black, H., \& Walker, D. O. (2018). Attachment theory at work: A review and directions for future research. Journal of Organizational Behaviour, 39(2), 185-198. doi:10.1002/job.2204

Zenger, J., \& Folkman, J. (2014). Feedback: The Powerful Paradox. In Zenger Folkman. Retrieved October 9, 2018, from https://zengerfolkman.com/wp-content/uploads/2013/03/ZFFeedback-The-Powerful-Paradox.pdf 